УДК [378.091.212]:316.7

DOI:

Катерина Осадча, доктор педагогічних наук, доцент, доцент кафедри інформатики $і$ кібернетики Мелітопольського державного педагогічного університету імені Богдана Хмельницького

Вячеслав Осадчий, доктор педагогічних наук, професор, професор кафедри інформатики і кібернетики

Мелітопольського державного педагогічного університету імені Богдана Хмельницького Олег Спірін, доктор педагогічних наук, професор, проректор з наукової роботи та циирровізації ДЗВО “Університет менеджменту освіти"

Владислав Круглик, доктор педагогічних наук, професор, професор кафедри інформатики і кібернетики

Мелітопольського державного педагогічного університету імені Богдана Хмельницького

\title{
РЕАЛІЗАЦІЯ ІНДИВІДУАЛІЗАЦІЇ ТА ПЕРСОНАЛІЗАЦІї НАВЧАННЯ ЗАСОБАМИ МОODLE
}

У статті проаналізовано засоби та інструментарій підтримки індивідуалізації й персоналізації навчання у системі дистанційного навчання Moоdle. У процесі професійної підготовки майбутніх фахівиів для підтримки індивідуалізаиії навчання засобами Mоодlе визначено налаштування окремих модулів, елементів та ресурсів платформи. Виділено основні переваги використання системи Моодlе для організаціі персоналізованого навчання: гнучкість, зручність, модульність, економічна ефективність, інтерактивність, різноманіття контролю знань, використання журналу оцінок, засоби планування.

Ключові слова: індивідуалізація; персоналізація навчання; професійна підготовка; системи дистанційного навчання; Moоdle.

Puc. 4. Лim. 9.

Kateryna Osadcha, Doctor of Sciences (Pedagogy), Associate Professor, Associate Professor of the Computer Science and Cybernetics Department, Bohdan Khmelnytsky Melitopol State Pedagogical University

Viacheslav Osadchyi, Doctor of Sciences (Pedagogy), Professor, Professor of the Computer Science and Cybernetics Department, Bohdan Khmelnytsky Melitopol State Pedagogical University Oleg Spirin, Doctor of Sciences (Pedagogy), Professor, Vice-rector of Research and Digitalization,

State Higher Educational Institution "University of Educational Management" Vladyslav Kruglyk, Doctor of Sciences (Pedagogy), Professor, Professor of the Computer Science and Cybernetics Department,

Bohdan Khmelnytsky Melitopol State Pedagogical University

\section{IMPLEMENTATION OF INDIVIDUALIZATION AND PERSONALIZATION OF LEARNING BY MEANS OF MOODLE}

Individualization and personalization of education become a necessary attribute of the quality for professional training of future professionals in the higher education system. It is determined that the appropriate means for its improvement are distance learning technologies, in particular the distance learning system Moodle. Based on the analysis of documentation and experience in Moodle, the article analyzes the tools and tools to support the individualization and personalization of learning in the distance learning system Moodle. In the process of professional training for future specialists to support the individualization of learning by means of Moodle, the settings of individual modules, elements and resources of the platform are determined. In particular, it is the formation of the content of the discipline in the form for a modular structure; creation of multilevel tests; use of tools for portfolio formation; means of forming a learning route by imposing the necessary restrictions on the elements of the course, tracking the level of assessment, multicriteria assessment; multivariate presentation of educational information; setting up mini-groups; use of a system roles; application of mobile learning technologies. The main advantages of using the Moodle system for the organization of personalized learning are highlighted: flexibility, convenience, modularity, cost-effectiveness, interactivity, a variety of knowledge control, the use of assessment logs, planning tools. The following means of personalizing learning in Moodle are defined: competence repository and competence progress block, so that each student can see on his / her own information page the degree mastery of 


\section{РЕАЛІЗАЦІЯ ІНДИВІДУАЛІЗАЦІЇ ТА ПЕРСОНАЛІЗАЦЇ̈ НАВЧАННЯ ЗАСОБАМИМООDЦЕ}

certain competencies, and the teacher can monitor each student's progress and respond accordingly, as well as the "Icons" assessment element, which is a way to reflect the personal achievements and progress of the student in the study of the discipline.

Keywords: individualization; personalization of training; professional training; distance learning systems; Moodle.

$\Pi$ остановка завдання. Однією 3 найпоширеніших СДН в Україні й у світі $€$ Moodle [5], застосування якої в освітньому процесі, як вважають науковці [9], сприяє підвищенню мотивації здобувачів вищої освіти. Зважаючи на це, постало завдання проаналізувати можливості цієї платформи для забезпечення індивідуалізації і персоналізації навчання у процесі професійної підготовки майбутніх фахівців у закладах вищої освіти.

Аналіз наукових джерел. На думку науковців (С. Гончаренко [3], І. Шестопалова [10], Дж. Браун [1]), рівень професійної підготовки майбутніх фахівців у закладах вищої освіти можна удосконалити завдяки індивідуалізації та персоналізації навчання. В умовах актуалізації дистанційних технологій навчання, викликаних коронавірусною пандемією [6], важливими засобами для цього стають можливості систем (платформ) дистанційного навчання (СДН). Індивідуалізація є організацією такої системи взаємодії між учасниками процесу навчання, при якій найбільш повно використовуються індивідуальні особливості кожного, визначаються перспективи подальшого розумового розвитку і гармонійного вдосконалення особистісної структури, відбувається пошук засобів, які компенсували б наявні недоліки і сприяли формуванню індивідуального стилю діяльності майбутнього спеціаліста [3]. А персоналізація навчання - це особлива організація навчального процесу з метою набуття студентами суспільно значущих, індивідуально-неповторних властивостей і якостей, що дають змогу оригінально виконувати певну соціальну роль $[4,248]$. Для того, щоб реалізувати ці підходи в сучасних умовах навчання у закладах вищої освіти, доцільним є використання СДН з широкими налаштуванням і різноманітними можливостями.

Виклад основного матеріалу. Для підтримки індивідуалізації навчання у СДН Moodle $\epsilon$ такі переваги: створення курсу в СДН з дисципліни у вигляді модульної структури; формування модулів 3 доступністю матеріалу за результатами вивчення попередніх модулів і проходження проміжних тестів; створення навчальних матеріалів в СДН розгалуженої структури за заздалегідь створеним педагогічним сценарієм (Лекція зі зворотним зв'язком); створення ресурсів 3 додатковими можливостями опрацювання матеріалу для студентів зі слабкою підготовкою; створення багаторівневих тестів; створення i розміщення в курсі СДН індивідуальних завдань [2].

Найпростіший спосіб індивідуалізувати вивчення дисципліни - це створення в СДН мінігруп для оптимізації шляху їх навчального процесу. Створення завдань і навчальних матеріалів для груп залежно від вихідного рівня, освітніх особливостей і завдань, поставлених для досягнення цілей. Додавання до курсу додаткових матеріалів, які освоюють поглиблений i розширений матеріал. Крім того, в СДН Moodle зручно підтримувати розвиток і впровадження проєктної діяльності.

Інтеграція СДН Moodle можлива з різними інформаційними системами, що дає змогу створювати і зберігати електронне портфоліо. У портфоліо кожного студента зберігаються всі здані ним роботи, оцінки та коментарі викладача, повідомлення у форумі.

СДН Moodle пропонує такі інструменти для реалізації індивідуального підходу:

1. Інструменти формування маршруту навчання шляхом накладення необхідних обмежень на елементи курсу:

1.1. Відстеження виконання (перегляд, вивчення) елемента (рис. 1)

Залежно від виду діяльності, в курсі існують різні вимоги до завершення, наприклад, для елементів Файл, Сторінка, Папка основна вимога - це перегляд. Для Глосарію, крім основних вимог - перегляду і мінімальної оцінки, також можна встановити мінімальну кількість записів у цьому глосарії, які залишає кожен студент.

Для елемента Форум можна встановити такі вимоги, як певна кількість повідомлень / обговорень / відповідей, що дасть змогу індивідуально відстежувати активність студентів у цьому елементі курсу.

Для кожного оцінюваного ресурсу (Завдання, Тест) можна ставити прохідний бал.

1.2. Відстеження рівня оцінки

Цей параметр буде визначати мінімальну оцінку, необхідну для здачі. Це значення враховується при відстеженні виконання елементів або курсу. Оцінки вище прохідного балу виділяються у журналі зеленим кольором, а нижче - червоним. Елемент вважається виконаним, коли студент отримує оцінку. Для студентів будуть 


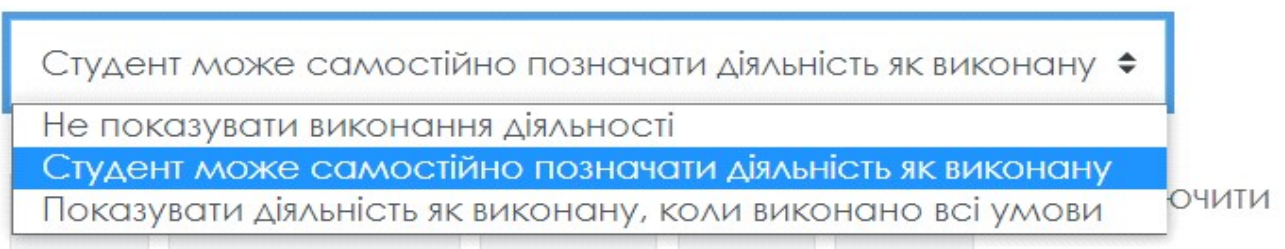

зберепти й повернутися до курсу

Рис. 1. Контроль за виконання елементів курсу у СДН Moodle

відображатися значки успішного або невдалого виконання.

2. Інструменти багатокритеріального оцінювання (Довідник оцінювача, Рубрики), при якому враховується складність матеріалу.

2.1. Довідник оцінювача - оцінювання на основі декількох критеріїв, за кожен 3 яких встановлюється свій максимальний бал.

Довідник оцінювача використовується в елементі Завдання і доступний тільки при виборі Довідник оцінювача в параметрах Метод оцінювання елемента. Він має такі параметри налаштування: редагування назви критерію, максимальний бал, опис для студентів та опис для оцінювачів. Сумарна оцінка за всі критерії не може перевищувати оцінку за завдання. Для цього виду оцінювання також можуть бути задані часто використовувані відгуки до виконаного завдання (рис. 2).

2.2. Метод оцінювання "Рубрика" - для кожного критерію викладач надає кілька рівнів знань і визначає можливу кількість балів для кожного з цих рівнів (Рис. 3).

3. Інструменти, що допомагають реалізувати багатоваріантність подання навчальної інформації в рамках єдиного дистанційного курсу.

Елемент Лекція дає змогу викладачеві розташовувати контент $\mathrm{i}$ / або практичні завдання (тести) в гнучкій формі. Викладач може використовувати лінійну схему лекції, що складається 3 кількох навчальних сторінок або створити деревоподібну схему, яка пропонує різні шляхи або варіанти для того, хто навчається. У будь-якому випадку для збільшення активної взаємодії і контролю розуміння викладачі можуть використовувати різні питання, такі як Множинний вибір, На відповідність і Коротка відповідь. Залежно від обраної студентом відповіді і стратегії, розробленої викладачем, студенти можуть перейти на іншу сторінку, повернутися на попередню або бути спрямованими індивідуальним шляхом.

4. Формування для кожної групи слухачів свого профілю подання навчального матеріалу.

Розподіл на групи може бути досить гнучким: за різними рівнями початкової підготовки, по успішності, за спеціалізацією тощо, що, значно допоможе реалізувати найбільш ефективну траєкторію навчання. Розподіл на групи може бути зроблено на двох рівнях: 1) рівень курсу передбачених на рівні курсу за замовчуванням для всіх видів діяльності, у рамках цього курсу; 2) рівень елемента - в кожному елементі курсу може бути заданий власний груповий метод, тобто будь-який елемент курсу може бути доступний тільки для членів однієї або декількох груп.

Розсилки оперативно інформують усіх учасників курсу або окремі групи про поточні події: не потрібно писати кожному студентові про нове завдання, група отримає повідомлення автоматично. Крім того в СДН Moodle дуже гнучка система ролей, яка уможливлює розширити систему прав студентів аж до повного злиття за можливостями 3 роллю вчителя, що допомагає педагогу перейти на новий щабель взаємовідносин зі студентами: він не просто дає своїм учням певний обсяг знань, а й надає їм 


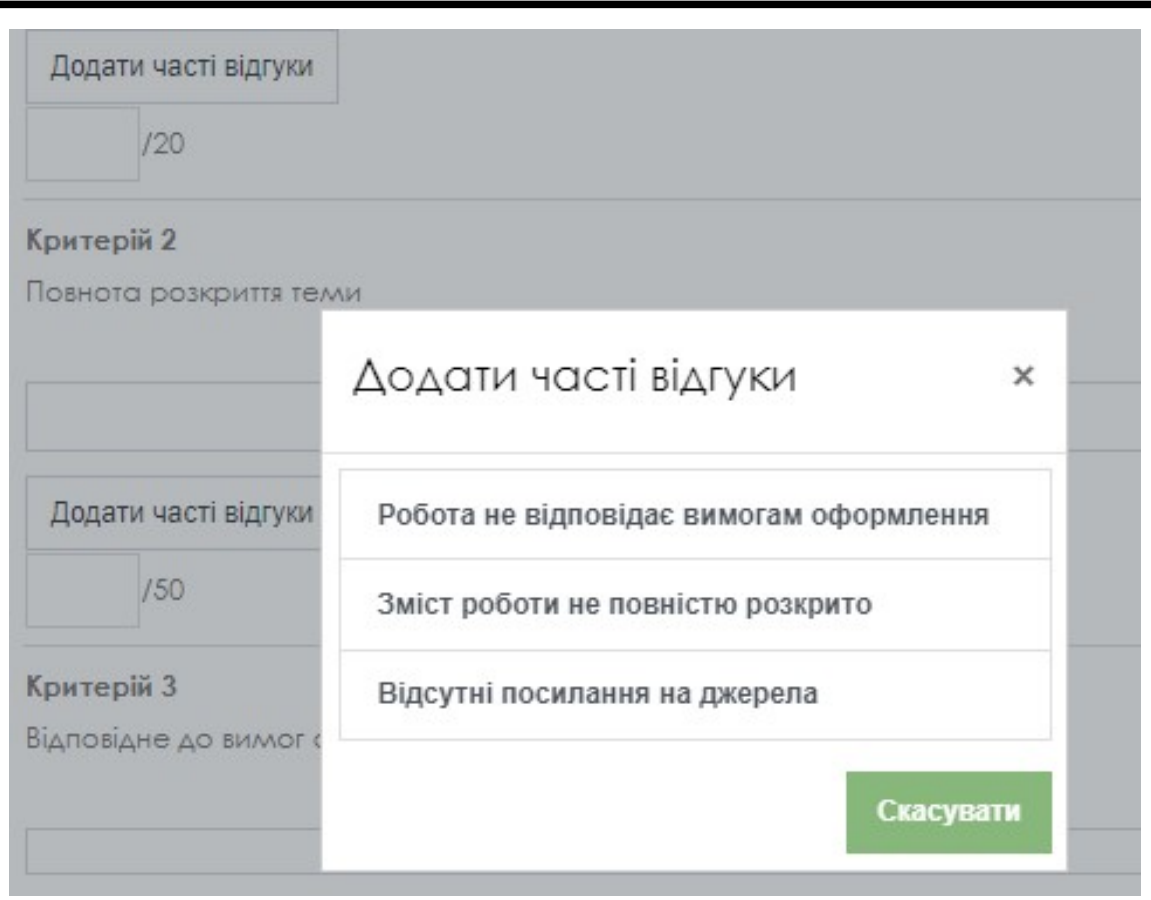

Рис. 2. Перелік коментарів для оцінюваного елемента у режимі “Довідник оцінювача" у СДН Mоodle

\begin{tabular}{|c|c|c|c|c|c|}
\hline $\begin{array}{l}\text { ВіАповіАність } \\
\text { технічного } \\
\text { завАання } \\
\text { вимогам } \\
\text { нормативних } \\
\text { Аокументів }\end{array}$ & $\begin{array}{l}\text { повністю не } \\
\text { віАповіАсе } \\
\text { вимогам } \\
\text { нормативних } \\
\text { Аокументів } \\
0 \text { балів }\end{array}$ & $\begin{array}{l}\text { практично } \\
\text { повністю не } \\
\text { віАповіАае } \\
\text { вимогам } \\
\text { нормативних } \\
\text { Аокументів } \\
1 \text { балів }\end{array}$ & $\begin{array}{l}\text { частково } \\
\text { віАповіАवе } \\
\text { вимотам } \\
\text { нормативних } \\
\text { Аокументів } \\
2 \text { балів }\end{array}$ & $\begin{array}{l}\text { практично } \\
\text { повністю } \\
\text { віАповіАсе } \\
\text { вимогам } \\
\text { нормативних } \\
\text { Аокументів } \\
3 \text { балів }\end{array}$ & $\begin{array}{l}\text { Повністю } \\
\text { віАповіАде } \\
\text { вимогам } \\
\text { нормативних } \\
\text { Аокументів } \\
4 \text { балів }\end{array}$ \\
\hline $\begin{array}{l}\text { віАповіАність } \\
\text { технічного } \\
\text { завАання }\end{array}$ & \multicolumn{2}{|c|}{ не віАповіАवе тематиці курсу } & \multicolumn{3}{|c|}{ віАповіАवе тематиці курсу } \\
\hline
\end{tabular}

Рис. 3. Оцінювання за у режимі “Рубрика” у СДН Moodle

можливість участі в навчальних ситуаціях, дозволяє всім учасникам навчального процесу ділитися ідеями, слухати інших, задавати питання, організовувати спілкування і брати участь у створенні контенту.

Індивідуалізація процесу навчання за допомогою Moodle може бути розширена і за рахунок мобільних технологій навчання [7]. Moodle $\epsilon$ WEB-орієнтованим середовищем, доступним як зі стаціонарних комп'ютерів, так і 3 усіх видів мобільних пристроїв через Інтернет. Мобільні технології дають істотно розширити i поліпшити можливості для навчання в самих різних умовах, це відмінний інструмент навчання для учнів, позбавлених можливості отримати якісну освіту, в силу різних причин. Крім доступу в Moodle через браузер мобільного телефона, існує мобільний додаток Moodle у App Store та Google play.

Мобільний додаток СДН Moodle має зручний інтерфейс і повний функціонал для роботи студентів із дистанційним курсом (Рис. 4).

До основних переваг використання системи Moodle для організації персоналізованого навчання слід віднести [8]:

1) гнучкість системи - можливість викладення матеріалу курсу з урахуванням рівнів підготовки та здібностей студентів; 


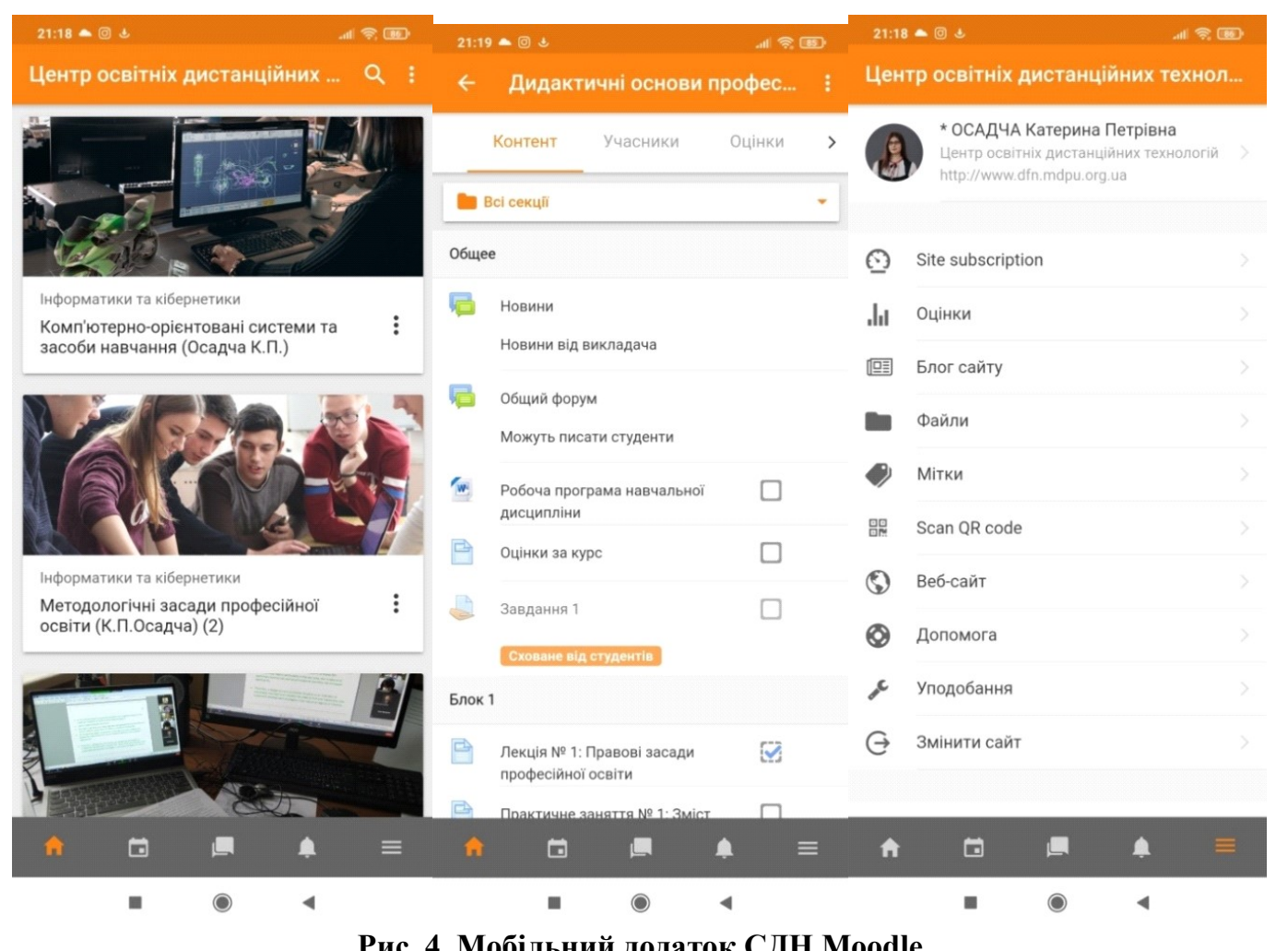

Рис. 4. Мобільний додаток СДН Moodle

2) зручність - навчання відбувається у зручний час для користувача;

3) модульність - навчальний матеріал розбитий на окремі теми, та відповідають здібностям студента;

4) економічна ефективність - порівняно 3 традиційним методом навчання значно дешевший;

5) інтерактивність - за допомогою різноманітних компонентів активне спілкування між викладачем та студентами групи;

6) різноманітні контролі знань (тестування, завдання, дискусіі);

7) журнал оцінок - користувач курсу може переглядати отримані оцінки;

8) планування - створення плану (траєкторії) навчання курсу для кожного студента.

Персоналізувати навчання майбутніх фахівців у закладі вищої освіти допоможе такий засіб Moodle, як репозиторій компетентностей і блок прогресу компетентностей. Завдяки цьому кожен зі студентів може побачити на власній інформаційній сторінці ступінь оволодіння певними компетентностями, а викладач - контролювати прогрес кожного студента і відповідним чином реагувати.

Для цієї мети в Moodle також доступний такий елемент оцінювання, як “Значки”. Значки хороший спосіб відобразити персональні досягнення і прогрес студента. Значки, отримані в освітньому середовищі Moodle, можуть відображатися у профілі користувача. Використання цього елемента дасть змогу не тільки оцінювати і заохочувати студентів, а й вносити до процесу навчання елемент гри, що посприяє появі здорового суперництва.

Висновки. Отже, індивідуалізація та персоналізація навчання стають необхідним атрибутом якості системи вищої освіти. Для підтримки індивідуалізації навчання засобами Moodle можна застосовувати різні налаштування окремих модулів, елементів та ресурсів, зокрема: формування змісту дисципліни у вигляді модульної структури; створення багаторівневих тестів; використання інструментів для формування портфоліо; засоби формування маршруту навчання шляхом накладення необхідних обмежень на елементи курсу, відстеження рівня оцінки, багатокритеріального оцінювання; багатоваріантність подання навчальної інформації; налаштування роботи мінігруп; використання системи ролей; застосування мобільних технологій навчання. Виділено основні переваги використання системи Moodle для організації персоналізованого навчання: гнучкість системи, зручність, модульність, економічна ефективність, інтерактивність, різноманітні контролі знань, журнал оцінок, планування. 


\section{ЛІТЕРАТУРА}

1. Brown J. Personalizing Post-Secondary Education: An Overview of Adaptive Learning Solutions for Higher Education. ITHAKA S+R, 2015. $35 \mathrm{p}$.

2.ГлотоваМ.Ю., СамохваловаЕ.А. Индивидуальные образовательные траектории на базе систем дистанционной поддержки образовательного процесса на примере СДО Moodle. Наука и школа. 2015. № 5. С. 60-68.

3. Гончаренко С.У., Володько В.М. Проблеми індивідуалізації процесу навчання. Педагогіка $i$ психологія. 1995. № 1. С. 63-71.

4. Коджаспирова Г.М., Коджаспиров А.Ю Словарь по педагогике. Москва: ИКЦ “МарТ”; Ростов н/Д: Издательский центр “МарТ”, 2005. $448 \mathrm{c}$.

5. Осадча К.П., Осадчий В.В. Технології дистанційного навчання. Робота 3 Moodle 2.4. Навчальний посібник. Мелітополь: Вид-во МДПУ ім. Б. Хмельницького, 2014. 396 с.

6. Осадча К.П., Осадчий В.В., Круглик В.С. Роль інформаційно-комунікаційних технологій під час епідемій: спроба аналізу. Ukrainian Journal of Educational Studies and Information Technology, 8 (1). C. 62-82. https://doi.org/10.32919/ uesit.2020.01.06

7. Осадчий В.В. Теорія і практика організації мобільної технології навчання у педагогічному університеті. Педагогічний дискурс. 2011. Вип. 9. С. 258-263.

8. Осадчий В.В., Крашеніннік I.B. LMS Moodle як інструмент персоналізації професійної підготовки майбутніх фахівців. Інформаційні технології в освіті, науці і техніці: тези доп. V Міжнар. наук.-практ. конф. (Черкаси, 21-23 травня 2020 p.). C. $169-170$.

9. Форостюк І. Підвищення мотивації молоді до вивчення іноземних мов у закладах вищої освіти. Молодь і ринок. 2018. № 7(162). С. 3640. DOI: https://doi.org/10.24919/2308-4634. 2018.140374 .

10. Шестопалова І.О. Індивідуалізація навчання іноземних мов у вищій школі Великої Британії: монографія. Київ: Науковий світ, 2004. 184 с.

\section{REFERENCES}

1. Brown, J. (2015). Personalizing Post-Secondary Education: An Overview of Adaptive Learning Solutions for Higher Education, 35 p. [in English].

2. Glotova, M. Yu., \& Samokhvalova, E. A. (2015). Individualnyye obrazovatelnyye trayektorii na baze sistem distantsionnoy podderzhki obrazovatelnogo protsessa na primere SDO Moodle [Individual educational trajectories based on the systems of distance support for educational process on the example of the LMS Moodle]. Science and School, 5, pp. 60-68. [in Russian].

3. Honcharenko, S.U., \& Volodko, V.M. (1995). Problemy indyvidualizatsii protsesu navchannia. Pedahohika i psykholohiia [Problems of individualization of the learning process]. Pedagogy and psychology, 1, pp. 63-71. [in Ukrainian].

4. Kodzhaspirova, G.M., \& Kodzhaspirov, A.Yu. (2005). Slovar po pedagogike [Dictionary of Pedagogy]. Moscow, 448 p. [in Russian].

5. Osadcha, K.P., \& Osadchyi, V.V. (2014). Tekhnolohii dystantsiinoho navchannia. Robota $\mathrm{z}$ Moodle 2.4 [Distance learning technologies. Working with Moodle 2.4]. Melitopol, 396 p. [in Ukrainian].

6. Osadcha, K., Osadchyi, V., \& Kruglyk, V. (2020). The role of information and communication technologies in epidemics: an attempt at analysis. Ukrainian Journal of Educational Studies and Information Technology, 8(1), pp.62-82. https:// doi.org/10.32919/uesit.2020.01.06. [in Ukrainian].

7. Osadchyi, V.V. (2011). Teoriia i praktyka orhanizatsii mobilnoi tekhnolohii navchannia $u$ pedahohichnomu universyteti [Theory and practice of organization of mobile learning technology in pedagogical university]. Pedagogical discourse, 9, pp. 258-263. [in Ukrainian].

8. Osadchyi, V.V., \& Krasheninnik, S.V. (2020). LMS Moodle yak instrument personalizatsii profesiinoi pidhotovky maibutnikh fakhivtsiv [LMS Moodle as a tool for personalizing the training of future professionals]. Informatsiini tekhnolohii $v$ osviti, nautsi $i$ tekhnitsi: tezy dop. V Mizhnar. nauk.-prakt. konf. (Cherkasy, 21-23 travnia 2020 r.) - An information technologies in education, science and technology: Abstracts of Papers of the V International Scientific-Practical Conf. (Cherkasy, May 21-23, 2020 p.).pp. 169-170. [in Ukrainian].

9. Forostyuk, I. (2018). Pidvyshchennia motyvatsii molodi do vyvchennia inozemnykh mov u zakladakh vyshchoi osvity [Improving motivation of young people to study foreign languages at higher education institutions]. Youth \& market, 7(162), pp. 36-40. https://doi.org/10.24919/2308-4634.2018.140374. [in Ukrainian].

10. Shestopalova, I.O. (2004). Indyvidualizatsiia navchannia inozemnykh mov u vyshchii shkoli Velykoi Brytanii [Individualization of foreign language teaching in higher education in Great Britain]. Kyiv, 184 p. [in Ukrainian].

Стаття надійшла до редакції 24.12.2020

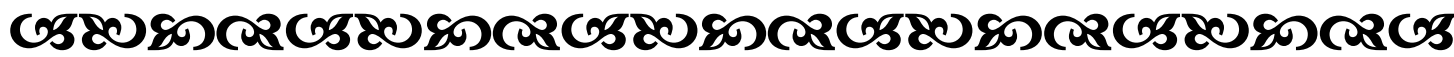

